\title{
Neural Correlates of Stroop Performance in Alzheimer's Disease: A FDG-PET Study
}

\author{
Je-Yeon Yun ${ }^{a}$ Dong Young Lee ${ }^{a, b}$ Eun Hyun Seo ${ }^{a, b}$ \\ II Han Choo ${ }^{a}$ Shin Young Park ${ }^{c}$ Shin Gyeom Kim ${ }^{\mathrm{e}}$ \\ Jong In Woo ${ }^{a}, b, d$ \\ ${ }^{a}$ Department of Neuropsychiatry, Seoul National University Hospital, b'Interdisciplinary \\ Program of Cognitive Science, Seoul National University, ${ }^{\circ}$ Department of Neuropsychiatry, \\ Daelim Saint Mary's Hospital and ${ }^{\mathrm{d}}$ Neuroscience Research Institute, Medical Research \\ Center, Seoul National University, Seoul, and e Department of Neuropsychiatry, \\ Soonchunhyang University Bucheon Hospital, Bucheon, Korea
}

\section{Key Words}

Alzheimer's disease $\cdot$ Neural correlates $\cdot$ PET $\cdot$ Prefrontal cortex $\cdot$ Stroop effect

\begin{abstract}
Background/Aims: The Stroop test is commonly applied in elderly subjects for the evaluation of cognitive impairment related to Alzheimer's disease (AD) and related disorders. This study aimed to investigate the functional neural correlates of the Stroop performance in AD. Methods: In 136 probable AD patients and 54 cognitively normal elderly, a $\left[{ }^{18} \mathrm{~F}\right]$-fluorodeoxyglucose positron emission tomography scan and Stroop Color Word Test (SCWT) were performed. The correlations between the Stroop effect, which was measured by 6 different scoring methods, and regional cerebral glucose metabolism ( $\mathrm{rCMglc}$ ) were explored using a region-of-interest (ROI) approach and voxel-based analysis. Results: Among 6 Stroop interference measures, only 2 scores, including the SCWT color-word (CW) score, were significantly correlated with rCMglc of the dorsolateral prefrontal and anterior cingulate ROls. Voxel-based analysis revealed significant positive correlations between SCWT CW scores and rCMglc in the inferior parietal lobule, middle temporal gyrus and middle frontal gyrus. Such correlations remained significant only in the less severe AD group. Conclusion: In AD patients, the Stroop effect depends on the functional integrity of the prefrontal cortices. Some parietotemporal regions also appear to be responsible for the Stroop effect in $A D$ individuals.

Copyright $\odot 2011$ S. Karger AG, Basel
\end{abstract}




\section{Introduction}

The Stroop task was originally developed by early experimental psychologists who found the so-called 'Stroop effect', which shows that reading the names of colors printed using nonmatching colored ink is always slower than simply naming colors or reading words alone [1]. The paradigm is known to measure selective attention or executive function, in terms of an individual's ability to suppress habitual responses in favor of unusual responses $[2,3]$. The Stroop test is widely used in clinical settings to differentiate, monitor, and describe various neuropsychiatric disorders $[4,5]$. In particular, it is very commonly applied in elderly subjects for the evaluation of cognitive impairment related to Alzheimer's disease (AD) and related disorders. It has also been found to sensitively differentiate patients with mild AD and mild cognitive impairment, a preclinical stage of $\mathrm{AD}$, from cognitively normal (CN) elderly individuals [6-9].

Findings from brain activation studies suggested that the prefrontal cortical areas, especially the dorsolateral prefrontal cortex (DLPFC) and anterior cingulate cortex (ACC), are closely associated with the Stroop effect $[5,9,10]$. It is, however, not clear whether or not the prefrontal cortical regions are the main pathoanatomical source for the impaired Stroop performance in $\mathrm{AD}$. Main AD pathologies, including neurofibrillary tangles and neuronal or synaptic loss, initially appear in the medial temporal cortex $[11,12]$ and then progress to posterior cortical areas, such as the lateral temporal and parietal cortices [13], while the frontal cortex is not involved until advanced stages of AD.

In order to identify the functional neuroanatomical correlates of Stroop performances in patients with $\mathrm{AD}$, we investigated the relationship between 6 kinds of Stroop interference (SI) scores reflecting the Stroop effect and regional cerebral glucose metabolism (rCMglc) measured by positron emission tomography (PET). We first tested whether or not the prefrontal dysfunction was related to SI scores in AD using a region-of-interest (ROI) approach. Secondly, we tried to explore overall neuroanatomical correlates of the SI scores through a voxel-based approach (VBA) without an a priori hypothesis.

\section{Patients and Methods}

\section{Subjects}

The study subjects were recruited from patients with $\mathrm{AD}$ who visited the Dementia and Age-Associated Cognitive Decline Clinic of the Seoul National University Hospital in Seoul. The study included 136 patients with AD who met the criteria for dementia of the Diagnostic and Statistical Manual of Mental Disorders [14] and criteria of probable AD of the National Institute of Neurological and Communicative Disorders and Stroke and the AD and Related Disorder Association [15]. Fifty-four CN elderly subjects were also selected from a pool of elderly volunteers with a normal neurologic and psychiatric history and examination, and a normal brain magnetic resonance imaging (MRI) scan. Exclusion criteria for this study were presence of any serious medical, psychiatric and/or neurological disorder that could affect mental function; evidence of focal brain lesions on MRI; the presence of severe behavioral or communication problems that would make a clinical or PET examination difficult; both- or left-handedness, and absence of a reliable informant. The Institutional Review Board of the Seoul National University Hospital, Korea, approved the study protocol, and informed consent was obtained from all subjects and their relatives. 
Clinical Assessments and Neuropsychological Tests

All of the subjects were examined by psychiatrists who had advanced training in neuropsychiatry and dementia research according to the protocol of the Korean version of the Consortium to Establish a Registry for AD (CERAD-K) Assessment Packet [16, 17]. Psychiatric, general physical and neurological examinations were performed along with routine laboratory tests and MRI of the brain. Reliable informants were interviewed to acquire accurate information regarding the cognitive, emotional and functional changes as well as the medical history of the subjects. Seven neuropsychological tests in the CERAD neuropsychological battery, including the Verbal Fluency - 'Animal Category', 15-item Boston Naming Test, Word List Memory, Word List Recall, Word List Recognition, Constructional Praxis and Constructional Recall $[16,17]$, were applied.

A panel consisting of four psychiatrists with expertise in dementia research made clinical decisions, including the clinical diagnosis and clinical dementia rating (CDR) [18], after reviewing all the available raw data. All clinical assessments were carried out within 3 weeks of the PET examination. None of the subjects was receiving any antidepressant or other psychotropic medication cholinesterase inhibitors.

\section{Stroop Color Word Test and SI Scores}

The standardized version of the Stroop Color Word Test (SCWT) [19] was used as the basis for the test used in the present study, but stimulus pages were modified for Korean elderly subjects [20]. The SCWT consists of 3 pages, each containing 100 items presented in 5 columns of 20 items. On the Word (W) page, the words 'red', 'yellow', and 'blue' translated into Korean were printed in black ink, whereas on the Color (C) page, stimuli were printed as $2 \mathrm{Xs}$ (XX) in red, yellow or blue, because in Korean the color words used had two letters on average (thus controlling for the size of colored regions on the page). The CW page contained the same color words printed in non-matching colors (e.g. 'red' printed in blue ink). When tested with the $\mathrm{W}$ page or the $\mathrm{CW}$ page, subjects were required to read the presented words as rapidly as possible in $45 \mathrm{~s}$. When using the $\mathrm{C}$ page, subjects were instructed to name the color of each XX [20].

Experienced clinical psychologists administered the SCWT test. The W, C and CW subscores refer to the number of items read or named correctly for each test page during the test performance in $45 \mathrm{~s}$.

The Stroop effect is defined as the extent of delay in naming the color of an incongruent color word relative to naming the color of a congruent color word or of a neutral non-color word [21]. The Stroop effect was measured by 6 SI scores calculated by 6 kinds of scoring methods. For SI scores, the scoring methods used in this study are described below.

SI-1: SI-1 is the raw score itself of the CW page of the SCWT (i.e. CW score) [19].

SI-2: SI-2 is the difference between the C and CW scores. A lower SI-2 score means less interference from incongruent words when naming the colors on the $\mathrm{CW}$ page [21].

SI-3: SI-3 is the ratio of $(\mathrm{C}-\mathrm{CW}) / \mathrm{C}$. Higher SI-3 means less interference from incongruent words when naming the colors in the CW condition [21].

SI-4: SI- 4 is the difference between the predicted CW score of $(\mathrm{W} \cdot \mathrm{C}) /(\mathrm{W}+\mathrm{C})$ and the $\mathrm{CW}$ score. This equation stems from the hypothesis that the time to name a $\mathrm{CW}$ item is equal to the time needed to suppress the reading of a word plus the time to identify a color [19].

SI-5: SI-5 is computed by the equation CW $-(\mathrm{W}+\mathrm{C}) / 2$ [22].

SI-6: SI-6 is calculated using the equation $(\mathrm{W}+\mathrm{CW})-\mathrm{C}$ [23].

\section{PET Image Acquisition and Preprocessing}

PET studies were performed using the ECAT EXACT 47 scanner (Siemens-CTI, Knoxville, Tenn., USA), which has an intrinsic resolution of $5.2-\mathrm{mm}$ full width at half maximum 
and images of 47 contiguous transverse planes with a 3.4-mm thickness for a longitudinal field of view of $16.2 \mathrm{~cm}$. Before administering $\left[{ }^{18} \mathrm{~F}\right]$-fluorodeoxyglucose (FDG), transmission scanning was performed using 3 germanium- 68 rod sources to correct the attenuation. Static emission scans began $30 \mathrm{~min}$ after the intravenous injection of $370 \mathrm{MBq}(10 \mathrm{mCi})\left[{ }^{18} \mathrm{~F}\right]$ FDG and were continued for $30 \mathrm{~min}$. All of the $\left[{ }^{18} \mathrm{~F}\right]-$ FDG PET scans were performed in a dimly lit room with minimal auditory stimulation during both the injection and PET scanning. Subjects were in a supine position with their eyes closed during the scan in order to minimize the confounding effects of any activity. The transaxial images were reconstructed using a filtered backprojection algorithm employing a Shepp-Logan filter with a cutoff frequency of 0.3 cycles/pixel as $128 \times 128 \times 47$ matrices with a size of $2.1 \times 2.1 \times 3.4 \mathrm{~mm}$.

Imaging data were analyzed using Statistical Parametric Mapping 2 (SPM2; Institute of Neurology, University College of London, UK) implemented in Matlab (Mathworks Inc., Natick, Mass., USA). Before statistical analysis, all images were spatially normalized to the Montreal Neurological Institute (MNI, McGill University, Montreal, Calif., USA) space to correct intersubject differences in brain morphology [24]. An affine transformation was performed to determine the 12 optimal parameters essential for registering the brain on the MNI template. Subtle differences between transformed images and the template were removed by a nonlinear registration method using the weighted sum of predefined smooth basis functions in a discrete cosine transformation. The glucose metabolism value of each voxel was normalized for the pontine value, which was extracted for each scan, because glucose metabolism in the pons tends to be relatively preserved in AD [25]. Normalized images were smoothed by convolution using an isotropic Gaussian kernel with $16-\mathrm{mm}$ full width at half maximum to accommodate intersubject differences in brain morphology and to increase dataset signal-to-noise ratio.

\section{PET Image Analysis}

CN Group versus Total AD Group

For additional confirmation of clinical AD diagnosis in AD subjects, differences in glucose metabolism between the $\mathrm{AD}$ and the $\mathrm{CN}$ groups were measured on a voxel-by-voxel basis using the 2-sample $t$ test of SPM2. The resulting set of $t$ values constituted the SPM(t) map. The SPM(t) was then transformed into a normal distribution to give a $\operatorname{SPM}(Z)$ [familywise error (FWE)-corrected $\mathrm{p}<0.05, \mathrm{k}>50][26,27]$.

Relationship between SI Scores and rCMglc

To investigate the relationship between SI scores and rCMglc, we used two different approaches: an ROI-based approach with a hypothesis and VBA without a hypothesis.

ROI-Based Approach. The automatic anatomic labeling (AAL) algorithm and a regioncombining method $[28,29]$ were applied to set ROIs to measure regional brain metabolism in the 6 prefrontal areas - bilateral DLPFC (AAL template Nos. 03-04 and 07-08), bilateral orbitofrontal cortex (OFC; A AL template Nos. 05-06, 09-10, 15-16, 21-22, 25-26 and 27-28) and bilateral ACC (AAL template Nos. 31-32; fig. 1).

Correlations between rCMglc in each ROI and 6 SI scores were tested by partial correlation analysis controlling for age, gender and education (SPSS, Cary, N.C., USA). The level of statistical significance for ROI-based analyses was set at 2-tailed $p<0.0083$ (Bonferroni corrected).

Voxel-Based Approach. Correlations between the SI-1 score and rCMglc were additionally examined through VBA. VBA is a technique for assessing regional changes in brain tissue content over the entire brain on a voxel-by-voxel basis without the need for an a priori ROI. VBA was conducted using the 'Single Subject: Covariates Only' menu of SPM2, with 3 variables of age, gender and education included as nuisance variables within the AD group 

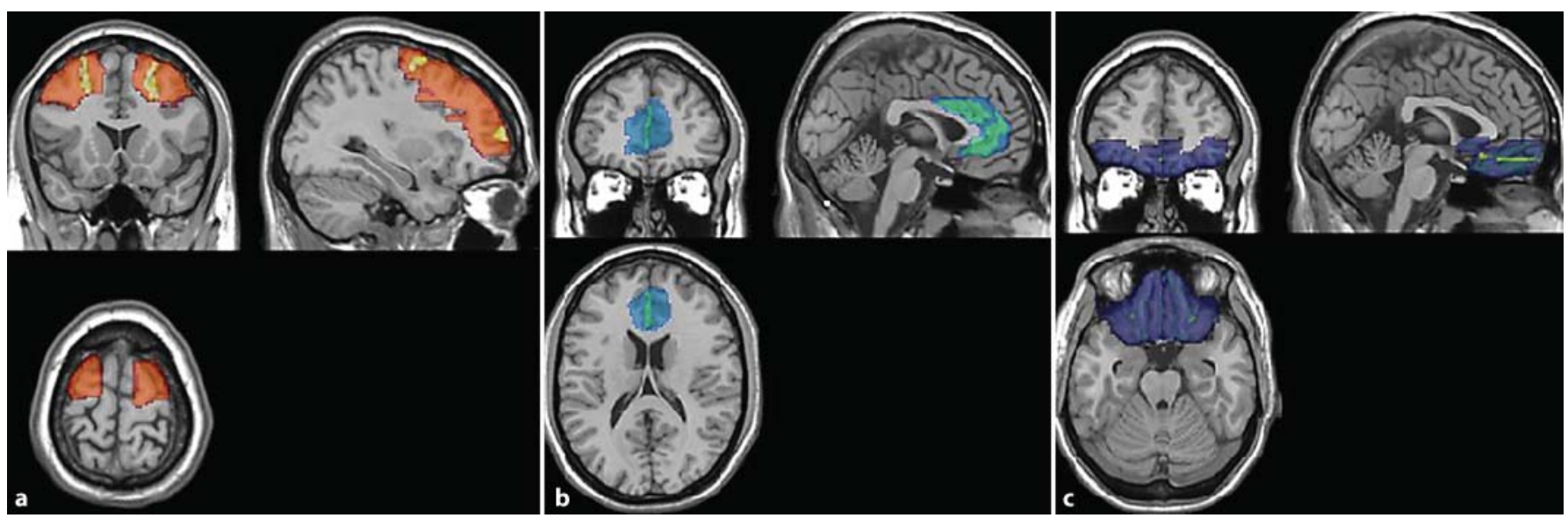

Fig. 1. Illustration of the three pairs of prefrontal ROIs used in this study. a Bilateral DLPFCs. b Bilateral ACCs. c Bilateral OFCs.

[20]. The resulting set of $t$ values constituted the $\operatorname{SPM}(\mathrm{t})$ map. The $\operatorname{SPM}(\mathrm{t})$ was then transformed into a normal distribution to give a $\operatorname{SPM}(\mathrm{z})$ (FWE-corrected $\mathrm{p}<0.05, \mathrm{k}>50)[26,27]$.

\section{Statistical Analysis of Demographic and Neuropsychological Data}

The demographic and clinical data for $\mathrm{AD}$ and $\mathrm{CN}$ subjects were compared with an independent $t$ test for continuous variables and $\chi^{2}$ tests for categorical variables, using SPSS 18.0.

\section{Results}

\section{Demographic and Clinical Characteristics of the Subjects}

Demographic and clinical characteristics of the subjects are shown in table 1 . There were no significant differences in age, education and gender between $\mathrm{CN}$ and $\mathrm{AD}$ group. The patients with AD showed a significantly lower mean Mini-Mental State Examination (MMSE) score than the $\mathrm{CN}$ group $(\mathrm{t}=19.17, \mathrm{p}<0.001)$. The $\mathrm{AD}$ group included 66 patients with very mild (CDR 0.5), 55 with mild (CDR 1) and 15 with moderate AD (CDR 2). Twenty-two AD patients were taking cholinesterase inhibitors [donepezil (21 patients) and rivastigmine (1 patient)]. No subject took memantine.

\section{Stroop Test and Other Neuropsychological Test Scores in AD}

With respect to all 8 neuropsychological tests, there were significant differences between the AD and CN groups $(\mathrm{p}<0.001)$. Regarding the Stroop performance, the CN group was significantly better than the AD group in all 3 subscores (C, W and CW; $\mathrm{p}<0.001$; table 1 ).

\section{Comparison of rCMglc between $A D$ and CN Groups}

Figure 2 shows the brain areas with significantly lower rCMglc in the AD group than in the CN group (FWE-corrected $\mathrm{p}<0.05, \mathrm{k}>50$ ), documenting the expected hypometabolism in the bilateral superior frontal gyri [Brodmann's area (BA) 8, BA 10], the bilateral middle frontal gyri (BA 8, BA 10, BA 11, BA 46), the bilateral inferior frontal gyri (BA 45, BA 47), the right medial frontal gyrus (BA 25), the bilateral rectal gyri (BA 11), the right ACC (BA 25 ), the left posterior cingulate gyrus (BA 31 ), the right caudate nucleus, the bilateral uncus 
Fig. 2. Statistical parametric maps showing decreased rCMglc in the total AD group compared with the $\mathrm{CN}$ elderly group (FWE-corrected $\mathrm{p}<$ $0.05, \mathrm{k}>50)$.

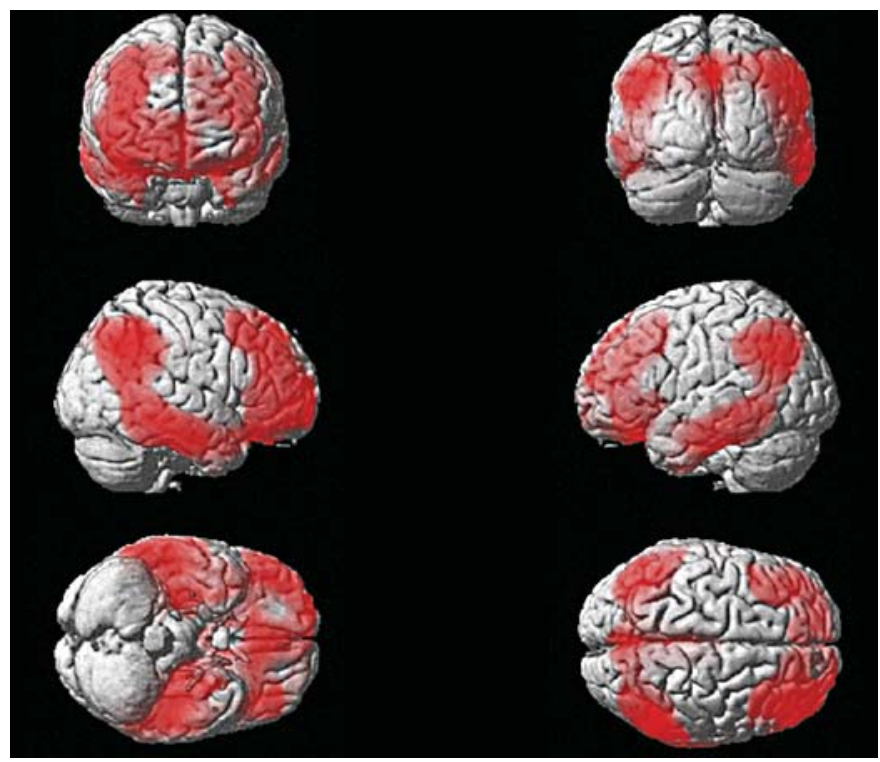

Table 1. Demographic characteristics and neuropsychological test results of the subjects

\begin{tabular}{lccc}
\hline & $\begin{array}{l}\mathrm{CN} \\
(\mathrm{n}=54)\end{array}$ & $\begin{array}{l}\mathrm{AD} \\
(\mathrm{n}=136)\end{array}$ & p value \\
\hline Age, years & $70.4 \pm 5.7$ & $70.2 \pm 8.4$ & 0.847 \\
Education, years & $10.2 \pm 4.4$ & $8.8 \pm 5.2$ & 0.099 \\
Gender, \% female & 66.7 & 75 & 0.245 \\
MMSE & $26.8 \pm 2.3$ & $16.6 \pm 5.1$ & $<0.001^{\mathrm{a}}$ \\
SOB & 0 & $4.7 \pm 2.3$ & \\
Neuropsychological tests & & & \\
$\quad$ Verbal Fluency (J1) & $16.0 \pm 5.0$ & $8.2 \pm 3.8$ & $<0.001$ \\
Boston Naming Test (J2) & $11.9 \pm 2.5$ & $7.9 \pm 3.4$ & $<0.001$ \\
Word List Memory (J4) & $18.7 \pm 5.1$ & $9.0 \pm 4.4$ & $<0.001$ \\
Constructional Praxis (J5) & $10.4 \pm 0.9$ & $8.4 \pm 2.4$ & $<0.001$ \\
Word List Recall (J6) & $6.9 \pm 1.9$ & $1.1 \pm 1.4$ & $<0.001$ \\
Word List Recognition (J7) & $9.3 \pm 1.6$ & $4.4 \pm 3.0$ & $<0.001$ \\
Constructional Recall (J8) & $6.4 \pm 2.8$ & $1.6 \pm 2.2$ & $<0.001$ \\
SCWT & & & $<0.001$ \\
$\quad$ C score & $61.7 \pm 11.4$ & $40.8 \pm 17.6$ & $<0.001$ \\
$\quad$ W score & $75.5 \pm 15.0$ & $49.9 \pm 19.5$ & \\
CW score & $36.6 \pm 10.1$ & $19.1 \pm 13.3$ & \\
\hline
\end{tabular}

Values are means \pm SD. ${ }^{a}$ Uncorrected $\mathrm{p}<0.001$

(BA 28), the bilateral inferior parietal lobule (BA 40), the right parahippocampal gyrus (BA 37 ) and in the bilateral inferior temporal gyri (BA 20). No voxel was observed with significantly increased rCMglc in AD.

Correlations between SI Scores and rCMglc of the Prefrontal ROIs in AD

Among the 6 SI scores used in this study, SI-1 and SI-6 scores were significantly correlated with rCMglc of the bilateral DLPFC and bilateral ACC in the overall AD group, while SI-2, SI-4 and SI-5 scores were not correlated with the glucose metabolism of any prefrontal 
Table 2. Correlations between 6 SI scores and rCMglc of 6 ROIs in the AD group ${ }^{\mathrm{a}}$

\begin{tabular}{llrrrrrr}
\hline SI scores & & DLPFC_L & DLPFC_R & OFC_L & OFC_R & ACC_L & ACC_R \\
\cline { 3 - 7 } SI-1 & Correlation & 0.231 & 0.304 & 0.129 & 0.199 & 0.252 & 0.233 \\
& p value & $\mathbf{0 . 0 0 8}$ & $<\mathbf{0 . 0 0 1}$ & 0.141 & 0.022 & $\mathbf{0 . 0 0 4}$ & $\mathbf{0 . 0 0 7}$ \\
SI-2 & Correlation & -0.015 & 0.019 & 0.020 & 0.013 & -0.055 & -0.050 \\
& p value & 0.863 & 0.825 & 0.818 & 0.884 & 0.528 & 0.566 \\
SI-3 & Correlation & -0.299 & -0.270 & 0.005 & -0.065 & -0.171 & -0.156 \\
& p value & $<\mathbf{0 . 0 0 1}$ & $\mathbf{0 . 0 0 2}$ & 0.958 & 0.461 & 0.050 & 0.075 \\
SI-4 & Correlation & 0.133 & 0.162 & 0.051 & 0.103 & 0.172 & 0.157 \\
& p value & 0.128 & 0.063 & 0.560 & 0.238 & 0.049 & 0.072 \\
SI-5 & Correlation & -0.014 & -0.032 & -0.042 & -0.025 & 0.024 & 0.021 \\
& p value & 0.876 & 0.719 & 0.634 & 0.777 & 0.787 & 0.814 \\
SI-6 & Correlation & 0.261 & 0.301 & 0.160 & 0.205 & 0.279 & 0.259 \\
& p value & $\mathbf{0 . 0 0 3}$ & $<\mathbf{0 . 0 0 1}$ & 0.067 & 0.019 & $\mathbf{0 . 0 0 1}$ & $\mathbf{0 . 0 0 3}$ \\
\hline
\end{tabular}

a See the text for the definition of each SI score.

Significant correlations ( $\mathrm{p}<0.0083$, Bonferroni corrected, two tailed) are indicated with bold characters._L = Left;_R = right.

region. In contrast, the SI-3 score was only correlated with bilateral DLPFC metabolism (table 2). Referring to these results and the simplicity of scoring, we selected the SI-1 score as a representative score of SI effects for further analyses.

To explore the effect of global AD severity on the relationship between SI effect and rCMglc, we divided the patients with $\mathrm{AD}$ into two severity subgroups according to the CDR Sum of Boxes score (SOB): the less severe $\mathrm{AD}$ group (CDR SOB $\leq 4$, which equals the median CDR SOB score of all AD patients) and the more severe AD group (CDR SOB $>4$ ). Positive correlations between the SI- 1 score and rCMglc were found in all 6 prefrontal regions [partial correlation coefficient $\left(r_{p}\right)=0.408, p=0.001$ for the left DLPFC; $r_{p}=0.454, p<0.001$ for the right DLFPC; $r_{p}=0.385, p=0.001$ for the left ACC; $r_{p}=0.400, p=0.001$ for the right ACC; $r_{p}=0.336, p=0.006$ for the left OFC; $r_{p}=0.363, p=0.003$ for the right OFC] for the less severe subgroup, whereas no such correlations were found for the more severe subgroup.

Voxel-Based Correlations between SI Scores and rCMglc of the Whole Brain in AD

Using VBA (fig. 3; table 3), we found significant correlations between SI-1 scores and rCMglc of the left inferior parietal lobule, left middle temporal gyrus and left middle frontal gyrus in the total $\mathrm{AD}$ group. We also performed a subgroup analysis for each subgroup. In the less severe group (CDR SOB $\leq 4$ ), there were significant correlations between SI-1 scores and rCMglc in very similar but wider regions compared with regions found to be significant in the total AD group. In contrast, no significant correlations existed at the threshold level of $\mathrm{p}<0.05$ (FWE corrected).

\section{Discussion}

This is the first study to demonstrate functional neuroanatomical correlates in Stroop performance in AD patients. Our ROI-based approach confirmed that the Stroop effect shows a good correlation with rCMglc of the prefrontal cortices, including the bilateral DLPFCs and ACCs in AD. Applying VBA with no a priori hypothesis, we also found that rCMglc in the posterior cortical regions, including the left inferior parietal lobule, temporal 
Table 3. Brain areas showing significant correlations between the SI-1 score and rCMglc in the AD group ${ }^{1}$

\begin{tabular}{|c|c|c|c|c|c|c|c|c|}
\hline \multirow[t]{2}{*}{ Brain region } & \multirow[t]{2}{*}{$\mathrm{BA}$} & \multicolumn{3}{|c|}{ MNI coordinates } & \multirow[t]{2}{*}{ t-score } & \multirow[t]{2}{*}{ Z-score } & \multirow{2}{*}{$\begin{array}{l}\text { Corrected } \\
\text { p (FWE) }\end{array}$} & \multirow{2}{*}{$\begin{array}{l}\text { Cluster } \\
\text { extension }\end{array}$} \\
\hline & & $\mathrm{x}$ & $\mathrm{y}$ & $\mathrm{z}$ & & & & \\
\hline \multicolumn{9}{|l|}{ Whole AD group ${ }^{2}$} \\
\hline Lt inferior parietal lobule & 40 & -54 & -56 & 42 & 6.01 & 5.64 & $<0.001$ & 2,839 \\
\hline Lt middle temporal gyrus & 37 & -58 & -46 & -6 & 5.27 & 5.01 & 0.001 & \\
\hline Lt middle frontal gyrus & 9 & -46 & 12 & 36 & 5 & 4.77 & 0.003 & 373 \\
\hline \multicolumn{9}{|l|}{ Less severe group } \\
\hline Lt supramarginal gyrus & 39 & -60 & -64 & 32 & 6.08 & 5.38 & $<0.001$ & 11,161 \\
\hline Lt middle temporal gyrus & 39 & -58 & -68 & 30 & 5.98 & 5.31 & $<0.001$ & \\
\hline Lt superior temporal gyrus & 39 & -62 & -60 & 30 & 5.96 & 5.29 & $<0.001$ & \\
\hline Lt angular gyrus & 39 & -54 & -72 & 34 & 5.72 & 5.12 & $<0.001$ & \\
\hline Lt superior temporal gyrus & 41 & -46 & -40 & 10 & 5.37 & 4.86 & 0.001 & \\
\hline Lt insula & 13 & -28 & -30 & 14 & 5.09 & 4.64 & 0.003 & \\
\hline Lt cingulate gyrus & 31 & -8 & -36 & 38 & 5.08 & 4.64 & 0.003 & \\
\hline Lt precuneus & 31 & -12 & -54 & 32 & 5.07 & 4.63 & 0.003 & \\
\hline Lt inferior parietal lobule & 40 & -66 & -34 & 40 & 4.85 & 4.46 & 0.006 & \\
\hline Lt inferior temporal gyrus & 21 & -66 & -12 & -16 & 4.77 & 4.4 & 0.008 & \\
\hline Lt posterior cingulate & 30 & -20 & -66 & 10 & 4.63 & 4.28 & 0.013 & \\
\hline Lt fusiform gyrus & 19 & -24 & -64 & -6 & 4.62 & 4.28 & 0.013 & \\
\hline Lt superior frontal gyrus & 6 & -26 & 20 & 64 & 4.78 & 4.4 & 0.008 & 3,142 \\
\hline Lt middle frontal gyrus & 8 & -44 & 14 & 42 & 4.53 & 4.2 & 0.017 & \\
\hline Lt putamen & - & -20 & 10 & 6 & 4.29 & 4.01 & 0.035 & \\
\hline Rt middle frontal gyrus & 6 & 38 & 16 & 62 & 4.53 & 4.2 & 0.017 & 123 \\
\hline Rt angular gyrus & 39 & 54 & -62 & 36 & 4.32 & 4.03 & 0.031 & 375 \\
\hline Rt superior frontal gyrus & 10 & 32 & 52 & 16 & 4.25 & 3.97 & 0.039 & 86 \\
\hline
\end{tabular}

cortex, posterior cingulate cortex, precuneus and the prefrontal regions, is associated with the Stroop effect in AD.

Since the Stroop test has been regarded as the 'Frontal Function Test' [30], which mostly involves the DLPFC [31-38] and ACC [34, 35, 37-46], we used an ROI-based approach to confirm the correlation between the degree of the Stroop effect and rCMglc of the prefrontal cortices including bilateral DLPFCs and bilateral ACCs in the whole AD group. In this study, the previously proposed 6 scoring methods for SI reflecting the Stroop effect demonstrated different correlation patterns with prefrontal rCMglc. SI-1 [19] and SI-6 [23] scores were significantly correlated with bilateral DLPFC and ACC rCMglc, and the SI-3 score [21] showed significant correlation mainly with bilateral DLPFC rCMglc. In contrast, the other SI scores, including SI-2, SI-4 and SI-5, demonstrated no significant correlation with prefrontal area rCMglc. Our results support the importance of the prefrontal function for the Stroop effect in AD patients, which could be revealed only with the help of the proper SCWT SI scoring method.

Considering the ROI-based analysis results and the simplicity of the scoring method, we selected the SI-1 score as a representative of the Stroop effect for further VBA. For the total AD group, significant relationships between the Stroop effect and rCMglc of the left DLPFC, the inferior parietal lobule and the middle temporal cortex were found. This is in accordance with previous functional neuroimaging studies, which indicated that the Stroop effect is re- 


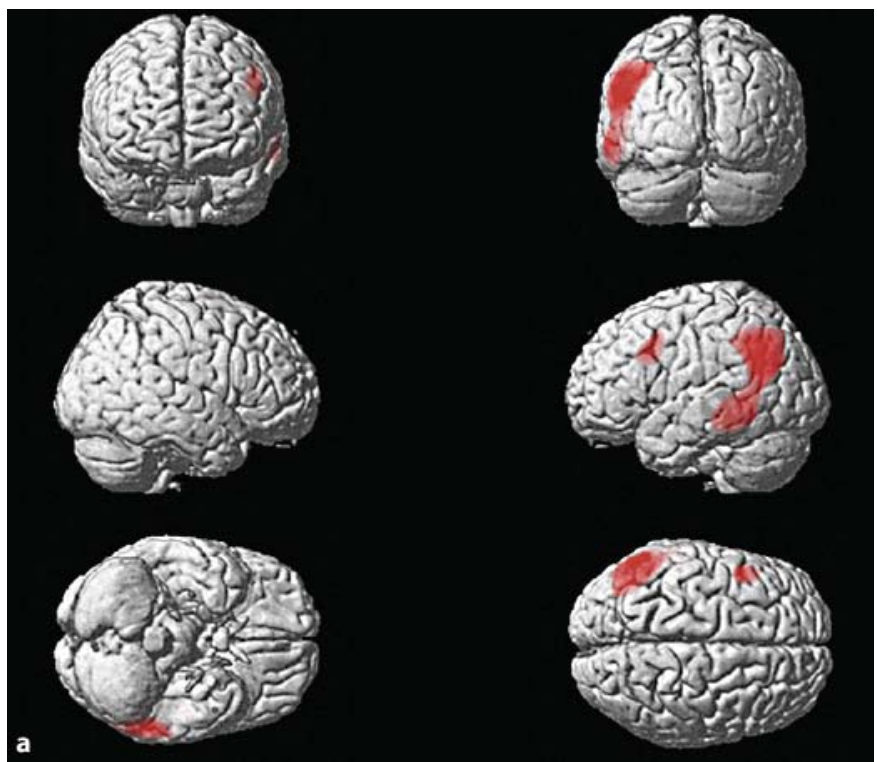

Fig. 3. Statistical parametric maps showing brain areas with positive correlation between the SI-1 score and rCMglc in the total AD group (a; FWE-corrected $\mathrm{p}<0.05, \mathrm{k}>50$ ) and in the less severe AD group (b; FWEcorrected $\mathrm{p}<0.05, \mathrm{k}>50$ ).

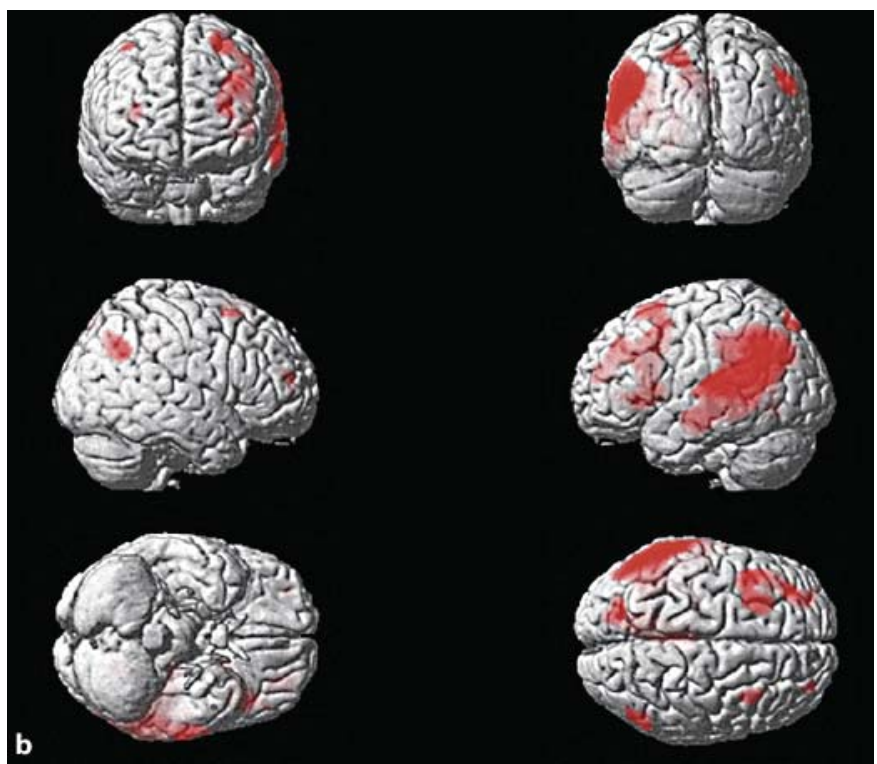

lated to the brain areas of the posterior parietal cortex [47], inferior parietal lobule [37, 40] and inferior temporal cortex [37]. Likewise, a postmortem brain study of AD patients showed that the degree of the Stroop effect was correlated with the increase in neurofibrillary tangles in the midfrontal area and the other diffuse cortical areas of the hippocampus, inferior parietal lobule and superior temporal cortex [8]. The results of the current study, together with those from previous ones, indicated that the Stroop effect was not only closely related with prefrontal activity but also with parietotemporal activity, supporting the 'parallel-distributed processing models' for the Stroop effect [48].

Because the brain areas involved in AD pathologies progressively expand as the clinical severity of AD increases [49], the neuroanatomical substrates related to the Stroop effect are expected to change from earlier to later stages of $\mathrm{AD}$. Therefore, we divided the AD patients into two subgroups based on the severity of SOB, and explored the relationship between the 
Stroop effect and regional brain function separately within each subgroup. For the less severe group, the Stroop effect was closely associated with hypometabolism in brain regions similar to the regions with significant relationships between the Stroop effect and glucose metabolism in the whole AD group. Since the prefrontal cortex is typically affected in later stages of $\mathrm{AD}[11,12]$, the association between the Stroop effect and frontal function may be related with compensatory neuronal activation in the region to cover up the impairment in the medial temporal lobe $[50,51]$. However, this association was not found for more severe AD patients. The lack of an association between the Stroop effect and metabolism suggests that the Stroop task is not a valid measure for regional brain function in more severe AD. The paucity of association might be the result of a 'floor effect' of SI score, rCMglc or both in the relatively advanced stages of $\mathrm{AD}$.

In conclusion, this study showed functional neuroanatomical substrates of the Stroop effect in AD patients. Our results support the idea that the Stroop effect in AD patients depends on the functional state of prefrontal cortices, similar to the findings from brain activation studies. In addition, some parts of the parietotemporal region also appear to be responsible for the Stroop effect in AD individuals. In terms of the influence of disease severity, the paucity of a relevant neuroanatomical correlation with the Stroop effect in the more severe AD group suggests that SCWT might not be a proper neuropsychological measure of executive function in advanced $\mathrm{AD}$.

\section{Acknowledgments}

This study was supported by a grant from the Korea Healthcare Technology R \& D Project, Ministry of Health, Welfare \& Family Affairs, Republic of Korea (grant No. A092145).

\section{References}

$\rightarrow$ Stroop JR: Studies of interference in serial verbal reactions. J Exp Psychol 1935;18:643-662.

2 Spreen O, Strauss E: A Compendium of Neuropsychological Tests. New York, Oxford University Press, 1998.

3 Mitrushina MN: Handbook of Normative Data for Neuropsychological Assessment. New York, Oxford University Press, 2005.

-4 Goldberg E, Bougakov D: Neuropsychologic assessment of frontal lobe dysfunction. Psychiatr Clin North Am 2005;28:567-580, 578-579.

-5 Badzakovatrajkov G, Barnett K, Waldie K, Kirk I: An ERP investigation of the Stroop task: the role of the cingulate in attentional allocation and conflict resolution. Brain Res 2009;1253:139-148.

-6 Kramer JH, Nelson A, Johnson JK, Yaffe K, Glenn S, Rosen HJ, Miller BL: Multiple cognitive deficits in amnestic mild cognitive impairment. Dement Geriatr Cogn Disord 2006;22:306-311.

-7 Perry RJ, Watson P, Hodges JR: The nature and staging of attention dysfunction in early (minimal and mild) Alzheimer's disease: relationship to episodic and semantic memory impairment. Neuropsychologia 2000;38:252-271.

-8 Bondi MW, Serody AB, Chan AS, Eberson-Shumate SC, Delis DC, Hansen LA, Salmon DP: Cognitive and neuropathologic correlates of Stroop Color-Word Test performance in Alzheimer's disease. Neuropsychology 2002;16:335-343.

-9 Hutchison KA, Balota DA, Ducheck JM: The utility of Stroop task switching as a marker for earlystage Alzheimer's disease. Psychol Aging 2010;25:545-559.

-10 Zoccatelli G, Beltramello A, Alessandrini F, Pizzini FB, Tassinari G: Word and position interference in Stroop tasks: a behavioral and fMRI study. Exp Brain Res 2010;207:139-147.

- 11 Braak H, Braak E: Neuropathological stageing of Alzheimer-related changes. Acta Neuropathol 1991; 82:239-259. 
12 Ball MJ: Neuronal loss, neurofibrillary tangles and granulovacuolar degeneration in the hippocampus with ageing and dementia. A quantitative study. Acta Neuropathol 1977;37:111-118.

-13 Herholz K: FDG PET and differential diagnosis of dementia. Alzheimer Dis Assoc Disord 1995;9: 6-16.

14 American Psychiatric Association: Diagnostic and Statistical Manual of Mental Disorders: DSM-IVTR, ed 4. Washington, American Psychiatric Association, 2000.

- 15 McKhann G, Drachman D, Folstein M, Katzman R, Price D, Stadlan EM: Clinical diagnosis of Alzheimer's disease: report of the NINCDS-ADRDA Work Group under the auspices of Department of Health and Human Services Task Force on Alzheimer's Disease. Neurology 1984;34:939-944.

-16 Lee JH, Lee KU, Lee DY, Kim KW, Jhoo JH, Kim JH, Lee KH, Kim SY, Han SH, Woo JI: Development of the Korean version of the Consortium to Establish a Registry for Alzheimer's Disease Assessment Packet (CERAD-K): clinical and neuropsychological assessment batteries. J Gerontol B Psychol Sci Soc Sci 2002;57:P47-P53.

-17 Morris JC, Heyman A, Mohs RC, Hughes JP, van Belle G, Fillenbaum G, Mellits ED, Clark C: The consortium to establish a registry for Alzheimer's disease (CERAD). Part I. Clinical and neuropsychological assessment of Alzheimer's disease. Neurology 1989;39:1159-1165.

- 18 Hughes CP, Berg L, Danziger WL, Coben LA, Martin RL: A new clinical scale for the staging of dementia. Br J Psychiatry 1982;140:566-572.

19 Golden CJ, Freshwater SM: The Stroop Color and Word Test: A Manual for Clinical and Experimental Uses. Chicago, Stoelting, 2002.

-20 Seo EH, Lee DY, Choo 1H, Kim SG, Kim KW, Youn JC, Jhoo JH, Woo JI: Normative study of the Stroop Color and Word Test in an educationally diverse elderly population. Int J Geriatr Psychiatry 2008;23:1020-1027.

-21 Lansbergen MM, Kenemans JL, van Engeland H: Stroop interference and attention-deficit/hyperactivity disorder: a review and meta-analysis. Neuropsychology 2007;21:251-262.

-22 Valentijn SA, van Boxtel MP, van Hooren SA, Bosma H, Beckers HJ, Ponds RW, Jolles J: Change in sensory functioning predicts change in cognitive functioning: results from a 6-year follow-up in the Maastricht aging study. J Am Geriatr Soc 2005;53:374-380.

-23 Lee TM, Chan CC: Stroop interference in Chinese and English. J Clin Exp Neuropsychol 2000;22: 465-471.

-24 Shen S, Sterr A, Szameitat A: A template effect study on voxel-based morphometry in statistic parametric mapping. Conf Proc IEEE Eng Med Biol Soc 2005;3:3051-3054.

-25 Ishii K: Clinical application of positron emission tomography for diagnosis of dementia. Ann Nucl Med 2002;16:515-525.

-26 Chumbley J, Worsley K, Flandin G, Friston K: Topological FDR for neuroimaging. Neuroimage 2010; 49:3057-3064.

27 Pataky TC: Assessing the significance of pedobarographic signals using random field theory. J Biomech 2008;41:2465-2473.

-28 Tzourio-Mazoyer N, Landeau B, Papathanassiou D, Crivello F, Etard O, Delcroix N, Mazoyer B, Joliot M: Automated anatomical labeling of activations in SPM using a macroscopic anatomical parcellation of the MNI MRI single-subject brain. Neuroimage 2002;15:273-289.

-29 Heckemann RA, Hajnal JV, Aljabar P, Rueckert D, Hammers A: Automatic anatomical brain MRI segmentation combining label propagation and decision fusion. Neuroimage 2006;33:115-126.

30 Tranel D, Anderson SW, Benton A (eds): Development of the Concept of 'Executive Function' and Its Relationship to the Frontal Lobes. Amsterdam, Elsevier, 1994, vol 9, pp 125-148.

-31 Vendrell P, Junque C, Pujol J, Jurado MA, Molet J, Grafman J: The role of prefrontal regions in the Stroop task. Neuropsychologia 1995;33:341-352.

-32 Banich MT, Milham MP, Atchley R, Cohen NJ, Webb A, Wszalek T, Kramer AF, Liang ZP, Wright A, Shenker J, Magin R: fMRI studies of Stroop tasks reveal unique roles of anterior and posterior brain systems in attentional selection. J Cogn Neurosci 2000;12:988-1000.

-33 Banich MT, Milham MP, Atchley RA, Cohen NJ, Webb A, Wszalek T, Kramer AF, Liang Z, Barad V, Gullett D, Shah C, Brown C: Prefrontal regions play a predominant role in imposing an attentional 'set': evidence from fMRI. Brain Res Cogn Brain Res 2000;10:1-9.

-34 Carter CS, van Veen V: Anterior cingulate cortex and conflict detection: an update of theory and data. Cogn Affect Behav Neurosci 2007;7:367-379. 
- 35 Floden D, Vallesi A, Stuss DT: Task context and frontal lobe activation in the Stroop task. J Cogn Neurosci 2011;23:867-879.

-36 Perret E: The left frontal lobe of man and the suppression of habitual responses in verbal categorical behaviour. Neuropsychologia 1974;12:323-330.

- 37 Peterson BS, Kane MJ, Alexander GM, Lacadie C, Skudlarski P, Leung HC, May J, Gore JC: An eventrelated functional MRI study comparing interference effects in the Simon and Stroop tasks. Brain Res Cogn Brain Res 2002;13:427-440.

- 38 Stuss DT, Floden D, Alexander MP, Levine B, Katz D: Stroop performance in focal lesion patients: dissociation of processes and frontal lobe lesion location. Neuropsychologia 2001;39:771-786.

- 39 Bench CJ, Frith CD, Grasby PM, Friston KJ, Paulesu E, Frackowiak RS, Dolan RJ: Investigations of the functional anatomy of attention using the Stroop test. Neuropsychologia 1993;31:907-922.

-40 Brown GG, Kindermann SS, Siegle GJ, Granholm E, Wong EC, Buxton RB: Brain activation and pupil response during covert performance of the Stroop Color Word task. J Int Neuropsychol Soc 1999; 5:308-319.

- 41 Bush G, Whalen PJ, Rosen BR, Jenike MA, McInerney SC, Rauch SL: The counting Stroop: an interference task specialized for functional neuroimaging - validation study with functional MRI. Hum Brain Mapp 1998;6:270-282.

42 MacDonald AW 3rd, Cohen JD, Stenger VA, Carter CS: Dissociating the role of the dorsolateral prefrontal and anterior cingulate cortex in cognitive control. Science 2000;288:1835-1838.

$\checkmark 43$ Milham MP, Banich MT, Webb A, Barad V, Cohen NJ, Wszalek T, Kramer AF: The relative involvement of anterior cingulate and prefrontal cortex in attentional control depends on nature of conflict. Brain Res Cogn Brain Res 2001;12:467-473.

-44 Milham MP, Banich MT: Anterior cingulate cortex: an fMRI analysis of conflict specificity and functional differentiation. Hum Brain Mapp 2005;25:328-335.

-45 Pardo JV, Pardo PJ, Janer KW, Raichle ME: The anterior cingulate cortex mediates processing selection in the Stroop attentional conflict paradigm. Proc Natl Acad Sci USA 1990;87:256-259.

-46 Peterson BS, Skudlarski P, Gatenby JC, Zhang H, Anderson AW, Gore JC: An fMRI study of Stroop word-color interference: evidence for cingulate subregions subserving multiple distributed attentional systems. Biol Psychiatry 1999;45:1237-1258.

-47 Banich MT, Milham MP, Jacobson BL, Webb A, Wszalek T, Cohen NJ, Kramer AF: Attentional selection and the processing of task-irrelevant information: insights from fMRI examinations of the Stroop task. Prog Brain Res 2001;134:459-470.

-48 Cohen JD, Dunbar K, McClelland JL: On the control of automatic processes: a parallel distributed processing account of the Stroop effect. Psychol Rev 1990;97:332-361.

-49 Braak H, Braak E: Evolution of the neuropathology of Alzheimer's disease. Acta Neurol Scand Suppl 1996;165:3-12.

-50 Gould RL, Arroyo B, Brown RG, Owen AM, Bullmore ET, Howard RJ: Brain mechanisms of successful compensation during learning in Alzheimer disease. Neurology 2006;67:1011-1017.

- 51 Pariente J, Cole S, Henson R, Clare L, Kennedy A, Rossor M, Cipoloti L, Puel M, Demonet JF, Chollet F, Frackowiak RS: Alzheimer's patients engage an alternative network during a memory task. Ann Neurol 2005;58:870-879. 